\title{
Infrared and Electronic Spectroscopy of the Jet-cooled 5-Methyl-2- Furanylmethyl Radical Derived from the Biofuel 2,5-Dimethylfuran
}

Nathanael M. Kidwell, ${ }^{\text {a) }}$ Deepali N. Mehta-Hurt, ${ }^{\text {b) }}$ Joseph A. Korn, ${ }^{\text {c) }}$ and Timothy S. Zwier* Department of Chemistry, Purdue University, West Lafayette, IN 47907-2084, United States

\section{Page 2}

\section{Contents}

Experimental Methods for Detection of Products from Electric Discharge using 118 nm (VUV) and $193 \mathrm{~nm}$ (UVMPI)

Results and Analysis of the Products Detected from Electric Discharge

Page 3-5

Figure S1

Discussion on the Detection of Primary/Secondary Products from DMF Electrical Discharge

Figure S2

Page 6-7

Discussion on the Detection of Aromatic Species from DMF Electrical Discharge

Page 8

\section{Table S1}

Page 9

Table S2

Page 10

References

\footnotetext{
* Author to whom correspondence should be addressed: zwier@purdue.edu

a) Present address: Department of Chemistry, University of Pennsylvania, Philadelphia PA 19104-6323, USA.

b) Present address: Abbott Medical Optics, Inc., 510 Cottonwood Drive, Milpitas CA 95035, USA.

c) Present address: Department of Chemistry, University of Washington, Seattle WA 981951700, USA.
} 


\section{Experimental Methods}

A photoionization mass spectrum of the species generated upon electrical discharge of DMF was recorded using fixed-frequency $118 \mathrm{~nm}$ VUV ionization and ultraviolet multiphoton ionization (UVMPI) at $193 \mathrm{~nm}$. The tripled output (355 nm, $30 \mathrm{~mJ} / \mathrm{pulse})$ of a Nd:YAG laser was focused into a gas cell containing a Xe/Ar gas mixture that is phase-matched for tripling to generate fixed-frequency $118 \mathrm{~nm}(10.5 \mathrm{eV}, \sim 1-2 \mu \mathrm{J} /$ pulse $)$ radiation. VUV photoionization acts to ionize molecules with ionization thresholds below $10.5 \mathrm{eV}$, typically with minimal fragmentation, thus allowing detection of primary and secondary discharge products. Ionizing radiation at $193 \mathrm{~nm}$ was generated from an ArF excimer laser (GAM, $0.5 \mathrm{~mJ} / \mathrm{pulse}$ ), and its principal use is to selectively detect aromatic species generated upon electrical discharge. Since aromatics typically absorb near $193 \mathrm{~nm}$ and have ionization thresholds that can be obtained by two-photon excitation $(12.8 \mathrm{eV})$, they are more sensitively detected from the electrical discharge of DMF as a result. Nevertheless, the relative ion signals may not represent the true abundances since some species may have inherently larger absorption cross sections at $193 \mathrm{~nm}$.

\section{Results and Analysis}

The UVMPI mass spectrum utilizing $193 \mathrm{~nm}$ radiation is shown in Figure S1, where the higher mass products are more readily observed after a multiplicative factor $(\mathrm{x} 4)$ is applied. Similar to the DMF flame results, the m/z $104\left(\mathrm{C}_{8} \mathrm{H}_{8}\right), \mathrm{m} / \mathrm{z} 106\left(\mathrm{C}_{8} \mathrm{H}_{10}\right)$, and m/z $132\left(\mathrm{C}_{10} \mathrm{H}_{12}\right)$ are observed in the figure and were assigned in their study to styrene, ethylbenzene, and (E)-1phenyl-1-butene, respectively. Nevertheless, there are new aromatic product mass channels that are also readily detected in the figure that are not observed in the DMF flame results. Indeed, appreciable ion intensity in the $\mathrm{m} / \mathrm{z} 108\left(\mathrm{C}_{7} \mathrm{H}_{8} \mathrm{O}\right)$ and the $\mathrm{m} / \mathrm{z} 156\left(\mathrm{C}_{12} \mathrm{H}_{12}\right)$ channels is 
discernible. The next section will address the possible DMF decomposition pathways to account for the additional $\mathrm{m} / \mathrm{z}$ products observed in this work.

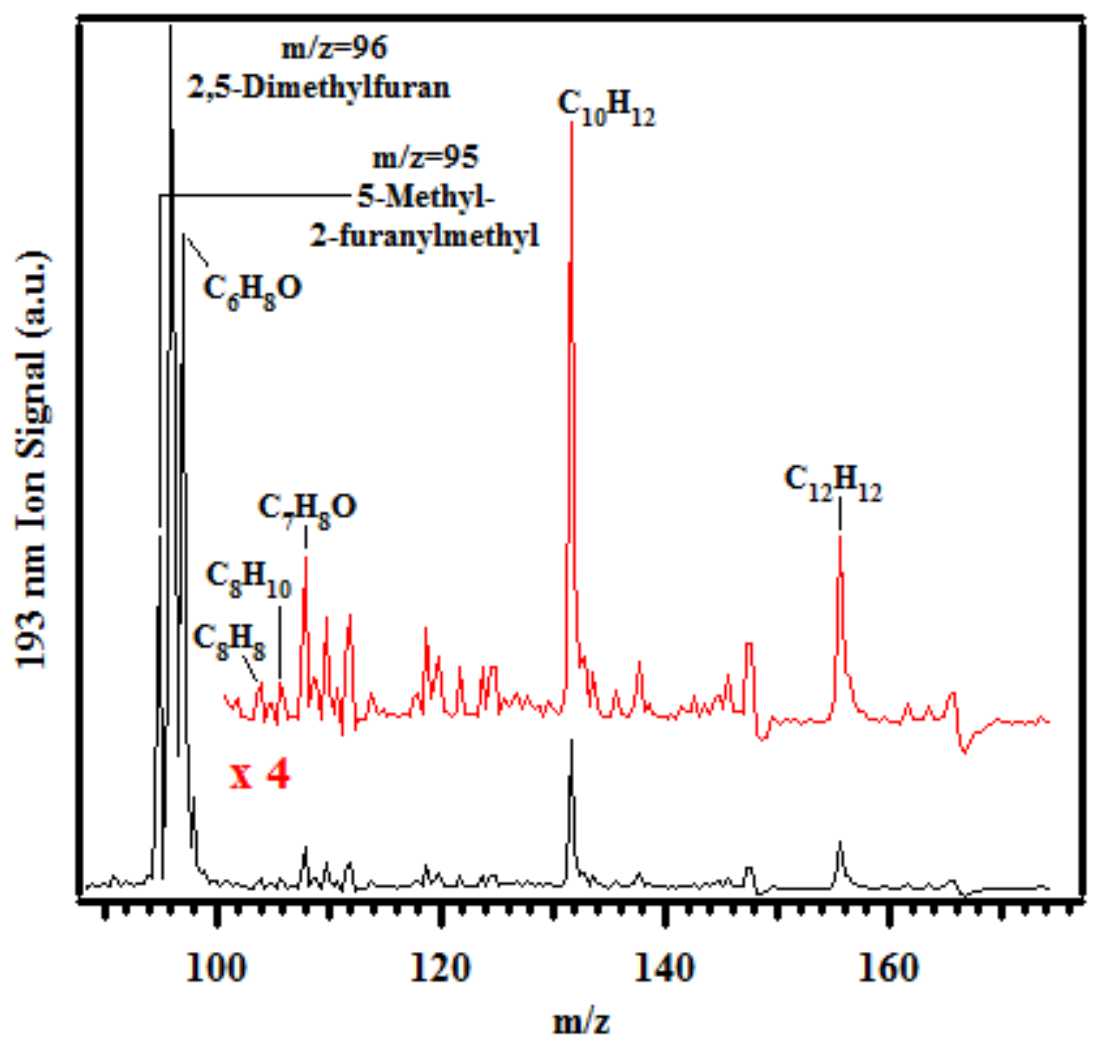

Figure S1. Difference mass spectrum recorded from the 2,5-dimethylfuran electrical discharge using $193 \mathrm{~nm}$ UVMPI. The inset shows the lower mass portion of the mass spectrum magnified $\mathrm{X} 4$.

\section{Discussion}

\section{Section S1. Detection of Primary/Secondary Products from DMF Electrical Discharge}

Upon initiating the decomposition of DMF using an electrical discharge, the neutral and intermediate species that were formed were detected using $118 \mathrm{~nm}$ ionizing radiation. The VUV technique is a single-photon $(118 \mathrm{~nm}=10.5 \mathrm{eV})$ method used as gentle and general ionization scheme and is coupled with time-of-flight detection for species present in the jet expansion. The focus of this section is to gain some insight to the formation pathways of the new 
primary/secondary discharge species from VUV detection subsequently generated from the electrical discharge of DMF.

Figure S2 summarizes the main unimolecular decomposition pathways of DMF found in the literature ${ }^{1-3}$ from flame and theoretical studies, in which the 5-methyl-2-furanylmethyl (MFM) radical is formed from $\mathrm{H}$ atom loss of the methyl group (labeled pathway (1)) and is highlighted in the figure. Continuing on in the same pathway, bond cleavage of the other methyl group $\mathrm{CH}$ leads to 2,5-dimethylene-2,5-dihydrofuran. Isomer products having the same mass as benzene (m/z 78) are made upon initial ring-opening of DMF via pathway (4), but requires a substantial amount of energy to break the furan ring. The $\alpha$ - and $\beta$-carbene intermediates are generated from DMF through either 2,3- $\mathrm{CH}_{3}$ group or 3,2-H atom migration, respectively, marked in the figure. Following pathway (2), methyl group migration to produce the $\alpha$-carbene requires approximately $80 \mathrm{kcal} / \mathrm{mol}$ of energy and generates propyne (m/z 40) and methylketene (m/z 56) upon ring-opening. Formation of the $\beta$-carbene intermediate through pathway (3) is also an endothermic process $(69 \mathrm{kcal} / \mathrm{mol})$, which eventually undergoes ring-opening to produce the stable molecule hexa-3,4-dien-2-one. 


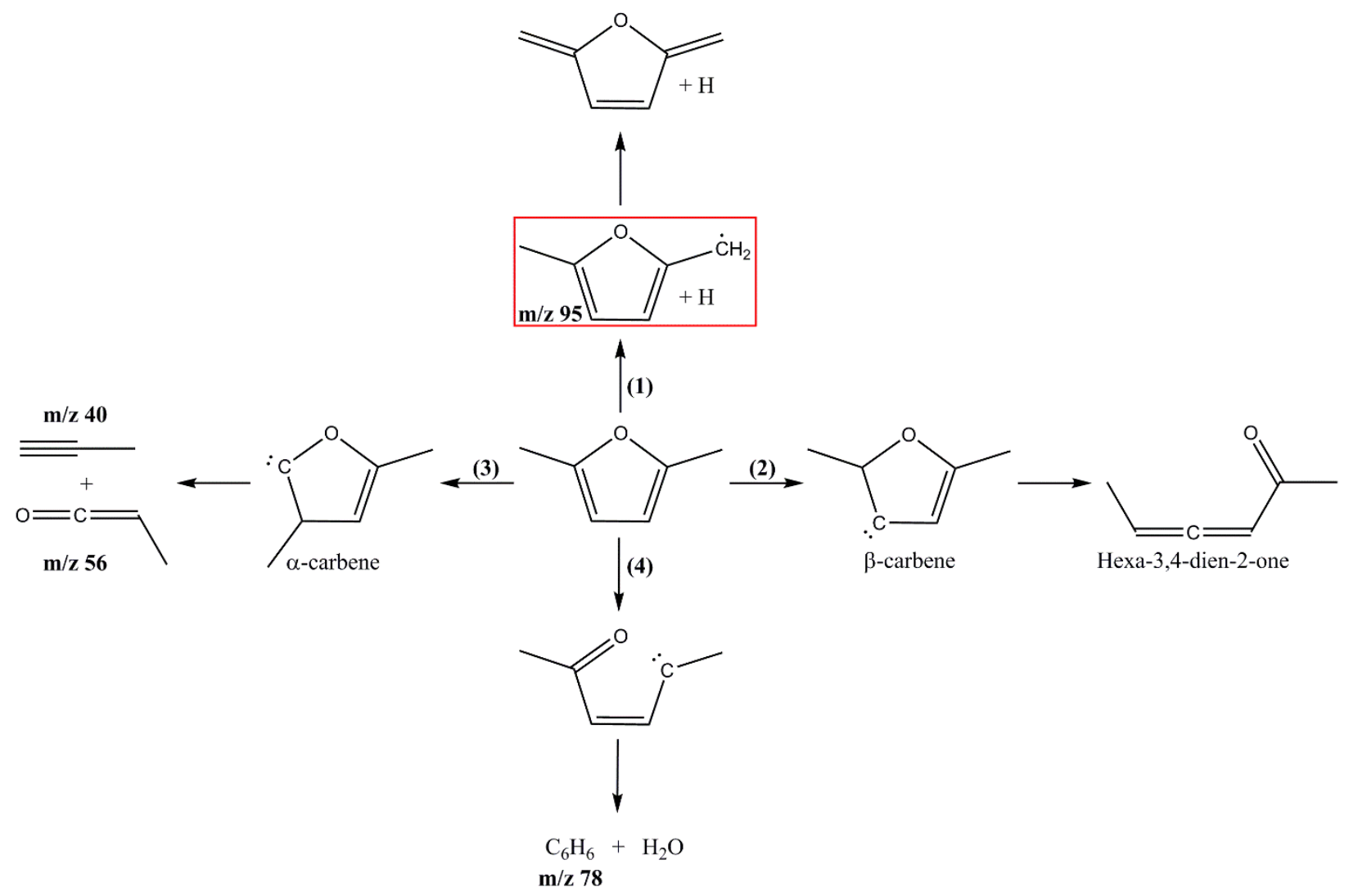

Figure S2. Summary of the unimolecular decomposition pathways of 2,5-dimethylfuran proposed in the literature. See text for discussion.

A theoretical chemical kinetic study of the unimolecular decomposition of DMF was carried out by Sirjean and co-workers ${ }^{1}$, in which they propose that at the pressure and temperature conditions relevant to combustion processes, hexa-3,4-dien-2-one decomposes to methylpropargyl (m/z 53) and acetyl radical (m/z 43) from initial C-C bond fission among other possibilities. In the study of DMF in a low-pressure, premixed laminar flame, Wu et. al. ${ }^{2}$ were able to identify methylpropargyl radical from the close agreement with the experimental and calculated ionization thresholds. However, no evidence of acetyl was found in their study. While we do not have conclusive evidence, we tentatively ascribe the $\mathrm{m} / \mathrm{z} 43$ peak observed in Figure 1 as belonging to the acetyl radical, with the methylpropargyl radical mass channel also 
recorded at $\mathrm{m} / \mathrm{z} 53$, which would be consistent with the results predicted from the model by Sirjean.

\section{Section S2. Detection of Aromatic Species from DMF Electrical Discharge}

Herein, we comment on the formation of new aromatic species generated upon discharge activation of DMF. Using $193 \mathrm{~nm}$ radiation to detect aromatic compounds, m/z 108 and m/z 156

species were newly observed in this work in contrast to previous work. ${ }^{2}$ Predicted to be the most facile decomposition route by $\mathrm{MFM}^{4}$, ring-opening followed by ring-enlargement to form cyclohexadienone is a dominant pathway to generate phenol by unimolecular reaction. However, bimolecular reactions can be envisaged where the cyclohexadienone generated may undergo $\mathrm{H}$-atom abstraction to form the phenoxy radical intermediate and eventual recombination with methyl radical to generate anisole $(\mathrm{m} / \mathrm{z} 108)$. Although there may be other species that may account for the m/z 108 peak observed in Figure S1, we postulate this as a potential mechanism by which anisole may be created and detected. Theoretical and experimental validation is needed to further support the assignment.

The peak at $\mathrm{m} / \mathrm{z} 156\left(\mathrm{C}_{12} \mathrm{H}_{12}\right)$ is by far the largest product channel observed in the UVMPI mass spectrum in Figure S1 and is newly detected in this work. There are numerous isomers and therefore pathways that can be responsible for this particular species, one of which includes the recombination of methylpropargyl radical with itself

$$
\mathrm{C}_{4} \mathrm{H}_{5}+\mathrm{C}_{4} \mathrm{H}_{5} \rightarrow \text { xylene isomers }
$$

similar to benzene formation from propargyl. ${ }^{5}$ Thereafter, reactions such as $\mathrm{H}$-atom abstraction to generate methylated benzyl radical isomers and reaction with vinylacetylene $(\mathrm{m} / \mathrm{z} 52)$ to yield the m/z 156 product following H-atom loss may be possible. Ring-closure products (e.g. dimethylnaphthalene) or singe-aromatic species are also potential spectral carriers. 
Dimethylnaphthalene may be formed from the $\alpha$-methylbenzyl radical (m/z 105), which is generated from $\mathrm{H}$-atom loss of ethylbenzne or $\mathrm{H}$-atom attack on styrene. ${ }^{6}$ Once produced, $\alpha$ methylbenzyl radical may recombine with methylpropargyl (m/z 53) and form dimethylnaphthalene $+2 \mathrm{H}$ following ring-closure. While most of the species present in the UVMPI spectrum of Figure S1 are even m/z, odd-mass products associated with free radicals are also observed. Some of the intensity in these mass channels may arise from fragmentation of stable molecules during the UVMPI process; however, others are due to free radicals produced by the discharge. One objective of future work could be to more fully characterize the species generated upon electrical discharge using similar methods utilized to characterize MFM. 
Table S1: Calculated vibrational modes in the ground electronic state for the 5-methyl-2furanylmethyl radical

\begin{tabular}{|c|c|c|}
\hline Mode & Frequency $\left(\mathrm{cm}^{-1}\right)$ & Symmetry \\
\hline 1 & 3270.92 & $\mathrm{~A}^{\prime}$ \\
\hline 2 & 3251.17 & $A^{\prime}$ \\
\hline 3 & 3234.94 & $A^{\prime}$ \\
\hline 4 & 3170.83 & $\mathrm{~A}^{\prime}$ \\
\hline 5 & 3117.99 & $\mathrm{~A}^{\prime}$ \\
\hline 6 & 3018.46 & $\mathrm{~A}^{\prime}$ \\
\hline 7 & 1575.14 & $\mathrm{~A}^{\prime}$ \\
\hline 8 & 1524.43 & $A^{\prime}$ \\
\hline 9 & 1484.40 & $\mathrm{~A}^{\prime}$ \\
\hline 10 & 1423.91 & $\mathrm{~A}^{\prime}$ \\
\hline 11 & 1409.24 & $\mathrm{~A}^{\prime}$ \\
\hline 12 & 1394.03 & $\mathrm{~A}^{\prime}$ \\
\hline 13 & 1307.33 & $\mathrm{~A}^{\prime}$ \\
\hline 14 & 1255.92 & $A^{\prime}$ \\
\hline 15 & 1219.67 & $A^{\prime}$ \\
\hline 16 & 1038.36 & $A^{\prime}$ \\
\hline 17 & 1020.73 & $\mathrm{~A}^{\prime}$ \\
\hline 18 & 977.54 & $A^{\prime}$ \\
\hline 19 & 955.19 & $\mathrm{~A}^{\prime}$ \\
\hline 20 & 908.93 & $\mathrm{~A}^{\prime}$ \\
\hline 21 & 725.53 & $\mathrm{~A}^{\prime}$ \\
\hline 22 & 622.73 & $\mathrm{~A}^{\prime}$ \\
\hline 23 & 411.46 & $\mathrm{~A}^{\prime}$ \\
\hline 24 & 272.92 & $\mathrm{~A}^{\prime}$ \\
\hline 25 & 3062.07 & $\mathrm{~A}^{\prime \prime}$ \\
\hline 26 & 1469.95 & $\mathrm{~A}^{\prime \prime}$ \\
\hline 27 & 1049.74 & $\mathrm{~A}^{\prime \prime}$ \\
\hline 28 & 854.63 & $\mathrm{~A}^{\prime \prime}$ \\
\hline 29 & 750.39 & $\mathrm{~A}^{\prime \prime}$ \\
\hline 30 & 710.90 & $\mathrm{~A}^{\prime \prime}$ \\
\hline 31 & 651.34 & $A^{\prime \prime}$ \\
\hline 32 & 605.59 & $\mathrm{~A}^{\prime \prime}$ \\
\hline 33 & 532.29 & $\mathrm{~A}^{\prime \prime}$ \\
\hline 34 & 281.28 & $\mathrm{~A}^{\prime \prime}$ \\
\hline 35 & 179.06 & $\mathrm{~A}^{\prime \prime}$ \\
\hline 36 & 138.35 & $\mathrm{~A}^{\prime \prime}$ \\
\hline
\end{tabular}


Table S2: Calculated vibrational modes in the first excited electronic state for the 5-methyl-2furanylmethyl radical

\begin{tabular}{|c|c|c|}
\hline Mode & Frequency $\left(\mathrm{cm}^{-1}\right)$ & Symmetry \\
\hline 1 & 3284.60 & $\mathrm{~A}^{\prime}$ \\
\hline 2 & 3256.98 & $\mathrm{~A}^{\prime}$ \\
\hline 3 & 3235.96 & $\mathrm{~A}^{\prime}$ \\
\hline 4 & 3177.51 & $\mathrm{~A}^{\prime}$ \\
\hline 5 & 1640.18 & $\mathrm{~A}^{\prime}$ \\
\hline 6 & 1507.73 & $\mathrm{~A}^{\prime}$ \\
\hline 7 & 1471.77 & $\mathrm{~A}^{\prime}$ \\
\hline 8 & 1437.49 & $\mathrm{~A}^{\prime}$ \\
\hline 9 & 1401.69 & $\mathrm{~A}^{\prime}$ \\
\hline 10 & 1363.78 & $\mathrm{~A}^{\prime}$ \\
\hline 11 & 1281.09 & $\mathrm{~A}^{\prime}$ \\
\hline 12 & 1243.54 & $\mathrm{~A}^{\prime}$ \\
\hline 13 & 1109.69 & $\mathrm{~A}^{\prime}$ \\
\hline 14 & 1072.73 & $\mathrm{~A}^{\prime}$ \\
\hline 15 & 1008.46 & $\mathrm{~A}^{\prime}$ \\
\hline 16 & 958.06 & $\mathrm{~A}^{\prime}$ \\
\hline 17 & 923.42 & $\mathrm{~A}^{\prime}$ \\
\hline 18 & 886.11 & $\mathrm{~A}^{\prime}$ \\
\hline 19 & 686.72 & $\mathrm{~A}^{\prime}$ \\
\hline 20 & 588.97 & $\mathrm{~A}^{\prime}$ \\
\hline 21 & 402.56 & $\mathrm{~A}^{\prime}$ \\
\hline 22 & 265.76 & $\mathrm{~A}^{\prime}$ \\
\hline 23 & 3110.01 & $\mathrm{~A}^{\prime \prime}$ \\
\hline 24 & 3047.03 & $A^{\prime \prime}$ \\
\hline 25 & 2884.83 & $\mathrm{~A}^{\prime \prime}$ \\
\hline 26 & 1454.25 & $\mathrm{~A}^{\prime \prime}$ \\
\hline 27 & 866.18 & $\mathrm{~A}^{\prime \prime}$ \\
\hline 28 & 839.71 & $\mathrm{~A}^{\prime \prime}$ \\
\hline 29 & 638.60 & $\mathrm{~A}^{\prime \prime}$ \\
\hline 30 & 617.46 & $\mathrm{~A}^{\prime \prime}$ \\
\hline 31 & 573.57 & $A^{\prime \prime}$ \\
\hline 32 & 386.58 & $\mathrm{~A}^{\prime \prime}$ \\
\hline 33 & 328.52 & $\mathrm{~A}^{\prime \prime}$ \\
\hline 34 & 218.44 & $\mathrm{~A}^{\prime \prime}$ \\
\hline 35 & 126.30 & $\mathrm{~A}^{\prime \prime}$ \\
\hline 36 & 114.50 & $\mathrm{~A}^{\prime \prime}$ \\
\hline
\end{tabular}




\section{References}

(1) Sirjean, B.; Fournet, R. Unimolecular Decomposition of 2,5-Dimethylfuran: A Theoretical Chemical Kinetic Study, Phys. Chem. Chem. Phys. 2013, 15, 596-611.

(2) Wu, X. S.; Huang, Z. H.; Yuan, T.; Zhang, K. W.; Wei, L. X. Identification of Combustion Intermediates in a Low-Pressure Premixed Laminar 2,5-Dimethylfuran/Oxygen/Argon Flame with Tunable Synchrotron Photoionization, Combust. Flame 2009, 156, 1365-1376.

(3) Simmie, J. M.; Metcalfe, W. K. Ab Initio Study of the Decomposition of 2,5-Dimethylfuran, J. Phys. Chem. A 2011, 115, 8877-8888.

(4) Sirjean, B.; Fournet, R. Theoretical Study of the Thermal Decomposition of the 5-Methyl-2furanylmethyl Radical, J. Phys. Chem. A 2012, 116, 6675-6684.

(5) Georgievskii, Y.; Miller, J. A.; Klippenstein, S. J. Association Rate Constants for Reactions Between Resonance-Stabilized Radicals: $\mathrm{C}_{3} \mathrm{H}_{3}+\mathrm{C}_{3} \mathrm{H}_{3}, \mathrm{C}_{3} \mathrm{H}_{3}+\mathrm{C}_{3} \mathrm{H}_{5}$, and $\mathrm{C}_{3} \mathrm{H}_{5}+\mathrm{C}_{3} \mathrm{H}_{5}$, Phys. Chem. Chem. Phys. 2007, 9, 4259-4268.

(6) Kidwell, N. M.; Reilly, N. J.; Nebgen, B.; Mehta-Hurt, D. N.; Hoehn, R. D.; Kokkin, D. L.; McCarthy, M. C.; Slipchenko, L. V.; Zwier, T. S. Jet-Cooled Spectroscopy of the aMethylbenzyl Radical: Probing the State-Dependent Effects of Methyl Rocking Against a Radical Site, J. Phys. Chem. A 2013, 117, 13465-13480. 